\title{
Entre la tecnología y la libertad: desafíos de ayer y de hoy
}

\section{Between technology and freedom: challenges of yesterday and today}

\author{
Cecilia E. Sturla ${ }^{1}$
}

Citar: Sturla, C. E. (2020). Entre la tecnología y la libertad: desafíos de ayer y de hoy. Cuadernos Universitarios, 13, pp. 29-36.

Recibido: setiembre 2020

Aceptado: octubre 2020

Ensayo científico

\section{Resumen}

En su libro El hombre unidimensional, escrito en 1964, Marcuse cuestiona la posibilidad de la libertad en una sociedad dominada por los medios de comunicación masiva, o mass media, según su expresión más usual. Una sociedad satisfecha tanto en su estilo de vida como en su organización termina dejando de lado la crítica que toda sociedad necesita para avanzar. Si los macrodatos — conocidos más comúnmente como big data - hacen superfluos los razonamientos porque todo está contenido en la red, el hombre termina siendo el resultado de un algoritmo manejado por quienes venden esos datos al mejor postor: sea a los gobiernos o a las empresas públicas o privadas. El control de la población no surge entonces de un esquema político-económico, sino de uno más abarcativo aún: la tecnología crea necesidades para el consumo y dentro del consumo se encuentra el tiempo libre que es dominado a través de la web y de los programas «à la carte».

Palabras clave: Marcuse - big data - humanidades - trabajo - ocio

\section{Abstract}

In his book The One-Dimensional Man, written in 1964, Marcuse questions the possibility of freedom in a society dominated by the mass media. A society satisfied both in its lifestyle and organization, ends up leaving aside the criticism that every society needs to move forward. If big data makes reasoning superfluous because everything is contained in the network, man ends up being the result of an algorithm managed by those who sell that data to the highest bidder:

1 Universidad Católica de Salta. Directora del Instituto de la Familia y la Vida Juan Pablo II de la misma Universidad. Profesora de Filosofía. 
be it governments, or public or private companies. The control of the population does not arise then from a political-economic scheme, but from an even more comprehensive one: technology creates needs for consumption and within consumption there is free time that is dominated through the web and programs «à la carte».

Keywords: Marcuse - big data - humanities leisure

\section{Introducción}

En su libro El hombre unidimensional, escrito en 1964, Marcuse cuestiona la posibilidad de la libertad en una sociedad dominada por los medios de comunicación masiva, o mass media, según expresión más usual: una sociedad satisfecha tanto en su estilo de vida como en su organización, termina dejando de lado la crítica que todo grupo humano necesita para avanzar (Marcuse, 1993, pág. 32). ¿Quién puede preocuparse de criticar a la política o al sistema político cuando se tiene el estómago lleno y los espacios de la vida privada y la diversión están también satisfechos? Si «la sustancia concreta de toda libertad» (Marcuse, 1993, pág. 31) depende de la independencia de la necesidad, al tener las necesidades satisfechas, la libertad queda subsumida en las exigencias económicas para, de esta manera, seguir con la propia forma de vida sin que ningún proceso revolucionario altere ese progreso indefinido.

Una tesis similar propone el filósofo surcoreano Byung-Chul Han.

Si los macrodatos hacen superfluos los razonamientos porque todo está contenido en la red, el hombre termina siendo el resultado de un algoritmo manejado por quienes venden esos datos al mejor postor: sea a los gobiernos o a las empresas públicas o privadas ¿Es el hombre quien hace el algoritmo o es el algoritmo quien configura al hombre? Lo diferente, sostiene Han, es lo igual, lo que hace que todos quieran poner like en las publicaciones que uniforman y están de acuerdo con lo que la sociedad requiere (Han, 2017).

\section{Tiempo libre}

¿Por qué el tiempo libre se volvió importante en las redes?

Porque siempre se lo identificó con el «ocio», es decir, con un espacio donde la libertad individual primaba sobre todas las demás cuestiones. Este ocio hace referencia a las actividades del hombre que lo conectan con su ser más íntimo, más profundo (Pieper, 1974). Es en ese espacio donde surgen las grandes preguntas existenciales, donde la imaginación, la inteligencia, el proyecto de vida, la creatividad, tienen su lugar. En este sentido, otium, es decir, ocio, se contrapone al neg-otium, al negocio, donde se desarrollan las acciones particulares y contingentes del hombre, pero que carecen de ese espacio de creatividad donde se manifiesta lo más personal y profundo de cada uno. Un hombre de negocios es un hombre ocupado en generar proyectos, inversiones, pero no tiene tiempo de detenerse en esos cuestionamientos existenciales que lo conectan con su ser más interior.

Adorno sostiene que, si antes se comprendía «tiempo libre» como «ocio», hoy se lo distingue de su opuesto «trabajo». Y en esa oposición, las fronteras se pierden, porque en parte Marx tenía razón: la sociedad burguesa transforma la fuerza-trabajo en mercancía. Por lo tanto, para que esta mercancía no pierda su 
valor, también debemos contemplar el tiempo libre como mercancía ${ }^{2}$.

El control de la población no surge entonces de un esquema político-económico, sino de uno más abarcativo aún: la tecnología crea necesidades para el consumo y dentro del consumo se encuentra el tiempo libre que es dominado a través de la web y de los programas «à la carte».

$\mathrm{Si}$ antes el problema era la búsqueda de un fundamento (ya sea metafísico, religioso, científico o lingüístico), ahora el problema pasó a ser quién ejerce el dominio de las cuestiones mecánicas de la comunicación, de la motivación y de la acción que genera la propaganda para la venta tanto de objetos de consumo, como de parámetros morales y políticos.

Solo queda definir bajo qué control quedará subsumido: si bajo el control policial, al estilo de Farenheit 451, o bajo el poder económico, que, mediante sus múltiples mecanismos, puede manejar a través del big data las necesidades y los intereses de todos quienes participan de las redes (Han, 2017).

La crítica de Marcuse hacia las nuevas formas de control desnuda el afán de dominio de una clase capitalista gobernada por una racionalidad tecnológica. Pero si bien Marcuse no podía anticiparse a la revolución ocasionada por Internet, sí pudo anticipar sus elementos más nocivos: «En virtud de la manera en que ha organizado su base tecnológica, la sociedad industrial contemporánea tiende a ser totalitaria» (Marcuse, 1993, pág. 33).
Cuando se aproximan elecciones en un país, solemos decir que el partido gobernante tiene una ventaja sobre la oposición, porque tiene el «aparato» del Estado a su favor. Y «aparato» es un objeto que sirve para desarrollar un trabajo o función determinada, por lo que, a través de diferentes mecanismos de control, puedo programar el «aparato» a los fines que quiera. Esto es, el poder totalizador de la tecnología queda evidenciado no solo en las políticas económicas (progresan únicamente los que se amparan bajo el sistema determinado) sino y, sobre todo, en el uso del tiempo libre de los ciudadanos. Por ello el big data se convierte en un instrumento con poderes cuasi infinitos a la hora de influir en las actitudes y preferencias ${ }^{3}$.

\section{Dominio y alienación}

La manera de pensar, inclusive los mismos temas a pensar son fagocitados por el esquema en el que están inmersos: los mass media (tanto la televisión, como la radio, como Internet) imponen un problema, todos los individuos nos creemos libres y por lo tanto opinamos de cualquier tema (y por consiguiente se ejerce la libre expresión) y así, a pesar de que muy poca gente conoce del tema en cuestión, todos ejercemos el derecho a opinar. Una vez impuesto el tema, el problema es determinar qué es lo justo y lo injusto. Pero el sistema ya dio su veredicto, y aquel que esté en contra de ese veredicto, es pasible de las críticas más lapidarias. Está prohibido disentir con el poderoso. Este

\footnotetext{
2 «Si es válida la idea de Marx de que en la sociedad burguesa la fuerza de trabajo se transforma en mercancía y, por tanto, el trabajo se convierte en cosa, la expresión hobby entraña la siguiente paradoja: esa actividad que se entiende a sí misma como lo contrario de toda cosificación, como reserva de vida inmediata en un sistema global absolutamente mediato, también se cosifica, a la par que el fijo límite entre trabajo y tiempo libre. En este se continúan las formas de la vida social organizada según el régimen de la ganancia.» (Adorno, 1993, pág. 56)

${ }^{3}$ Véase la influencia de Facebook sobre las elecciones de Estados Unidos contribuyendo a la victoria de Donald Trump. En: https://elpais.com/internacional/2016/12/06/mundo_global/1481046974_198482.html
} 
esquema hegeliano en su estructura (die Weltgeschichte ist das Weltgericht) marca entonces el totalitarismo de los sistemas tecnocráticos de comunicación. Queda definir entonces quién o quiénes gobiernan: ¿el Estado?, ¿las compañías transnacionales?

Con un celular abierto a la red sin control desde los 12 años, el adolescente promedio va construyendo un cúmulo de ideas que no provienen de su entorno, ni siquiera de su familia, sino de sitios que, sin necesidad de chequear las fuentes, van moldeando formas de pensamiento, eslóganes morales que se repiten de manera irreflexiva y banal. Es lo que Marcuse llama «el carácter racional de su irracionalidad» (Marcuse, 1993, pág. 39).

¿Cuál es la línea divisoria entre información y manipulación? Este tema no es nuevo: es fácil dirigir a una masa de gente que se deja llevar por la marea. Basta solo con mover las pasiones con un discurso encendido o con una propaganda medida en sus mínimos detalles. Por eso, para Platón y Aristóteles, la Retórica debe estar unida a la moral. Caso contrario, corre el riesgo de que sea utilizada para la manipulación de las masas. Hoy no es muy distinto de ayer: panem et circens, pasando por el aparato propagandístico de Göbbels y en alguna medida el cine on demand y las redes sociales (Han, 2017).

Aborto, eutanasia, educación sexual: temas difíciles, duros, en los cuales todos participan de manera activa para llevar a la audiencia a formar una opinión unívoca sin posibilidad de disenso. ¿Dónde queda entonces la libertad de conciencia, la libertad de prensa y la libertad de expresión? ¿A partir de qué principios los individuos opinamos sobre un tema y si ese tema está en contra del statu quo, qué mecanismos tenemos para expresarlo? El control social pasa a la tecnología y así todo está medido hasta el hartazgo: la audiencia manda, pero la audiencia se caracteriza por su volatilidad y volubilidad. Es una audiencia que, dada la velocidad de la comunicación, queda anestesiada para razonar. Todo mensaje se atomiza en fragmentos etarios y a través de los mecanismos de control, fácilmente manejables si se ejerce presión sobre el «aparato». E1 control social pasa por generar nuevas necesidades, por igualar las condiciones sociales desde los mass media y la tecnología. E1 mismo instrumento que comunica una noticia es el que manipula la venta de mercaderías y las opiniones a través de un eficaz y apabullante estudio psicológico para poder vender sea un reloj, sea la imagen de un político, sea una carrera universitaria.

En esta velocidad descontrolada para el consumidor, pero controlada por poderes intangibles, el juicio crítico y la capacidad de discernir se encuentran sometidos a una gran prueba: porque si la «libertad interior» no es tomada en cuenta, si ese espacio privado «en el cual el hombre puede convertirse en sí mismo y seguir siendo 'él mismo'» (Marcuse, 1993, pág. 40) desaparece del horizonte, entonces la libertad queda como una pantalla en la era tecnocrática.

La ideología se hace entonces más fuerte aún: pero ya no por una clase opresora sobre otra oprimida que se impondrá por la fuerza de las armas, sino que, en silencioso y tácito acuerdo, adoctrina a las masas que, incapacitadas de discernir lo bueno de lo malo, se dejan llevar por lo que dicen las redes, la televisión, la radio. Es esta ideología la que impone formas de pensar, de estar de acuerdo, de disentir, de formar una «falsa conciencia» que termina convirtiéndose, de acuerdo con Marcuse, en una «verdadera conciencia» (Marcuse, 1993, pág. 41). Pero lo «verdadero» no es más real ni más verdadero que lo «falso», por lo que podemos plantearnos con justa razón, si no somos como los hombres encerrados en 
la caverna ${ }^{4}$ que, imposibilitados de ver más allá de las sombras, nos conformamos con una realidad queriendo creer que lo que vemos es lo que es. Porque, ¿qué es lo real y qué lo virtual en esta sociedad mediatizada por los macrodatos? ¿Somos libres al elegir, si nuestros gustos nos los anticipa la web 3.0? De alguna manera Platón intuyó el riesgo que corremos los seres humanos al creer que las sombras en la caverna son verdaderas. Y los prisioneros encerrados en ella, por comodidad o pereza de ir más allá de lo meramente sensitivo, confunden lo verdadero con lo aparente. Tenemos entonces una sociedad que, alienada en sus gustos e intereses, acaba aceptando las «necesidades represivas», "por ignorancia y por derrotismo» (Marcuse, 1993, pág. 35).

El progreso técnico corre demasiado rápido para la mente del hombre que aún piensa desde los procesos y las relaciones. Los cambios no son asimilados desde una postura vital, sino que son tomados como vienen, sin poder discernir entre la bondad o maldad (o también neutralidad) del cambio mismo. Las nuevas tecnologías, por ser «nuevas», deben ser tomadas sin más, dejando al hombre a merced de las corporaciones que imponen esas tecnologías para sus propios fines.

Y así como la política exige al partido obediencia, las redes exigen al hombre obediencia a sus formas, a su vocabulario, a su prepotencia omnívoda. Twitter, Instagram, Facebook, Linkedin, todas las redes sociales exigen renovar contenidos, comentar de todo, no importa si se sabe o no del tema a tratar. Lo importante es figurar, estar en el comentario, ver la cantidad de likes que se obtienen de una vida que presume de ser auténtica. Porque no puede ser tal una vida si no se tiene tiempo para ser uno mismo, para vivir la vida y tomar las decisiones por uno y desde uno. No por la opinión de esa masa amorfa que conforman las redes sociales.

\section{Volver a uno mismo}

Los griegos entendieron el conocimiento de sí como base y fuente del pensamiento filosófico: «conócete a ti mismo», frase que estaba tallada en la entrada del Oráculo de Delfos. Sin la posibilidad de refugiarse en su yo interior, a través de lo cual el hombre es más sí mismo, la masa acrítica ejercerá su poder hipnótico dejando desprovisto el horizonte de razón y de ser.

Solo quien sabe ser desde uno puede volver a sí mismo a pesar de la fugacidad del mundo circundante. La tecnología nos envuelve de manera tal que, si no aprendemos a separarnos de ella, corremos el riesgo de alienarnos en ella y pensar como ella.

Leer a Marcuse hoy es adentrarse en las consecuencias de la descripción hecha con tanta anticipación. Toda la Escuela de Frankfurt, con sus matices, logró dar un diagnóstico de la segunda mitad del siglo XX. Tanto la Dialéctica de la Ilustración de Adorno y Horkheimer, como El hombre unidimensional, muestran rasgos de esta sociedad opulenta, que ByungChul Han retoma y exacerba. Donde hay mucho estímulo externo termina habiendo poca vida interior, poca libertad interior. El narcisismo provocado por la sociedad de consumo deja la exterioridad como anzuelo para pescar a quienes no pueden o no reconocen que la vida interior es previa a la exhibición frenética de todos los estados anímicos de las personas individuales.

Quizás la debilidad de la Escuela de Frankfurt no estuvo tanto en su diagnóstico cuanto en las salidas de esta sociedad opulenta.

\footnotetext{
4 Platón, La República, L. VII, 514a
} 
Y la salida del letargo (Komar, La salida del letargo, 2014), de la tiranía del big data, no es otra que el encuentro con las personas, el reflexionar sobre el proyecto de vida y ese proyecto de vida no puede darse sin los demás. La relacionalidad, la reciprocidad, la gratuidad, los vínculos, el contacto personal, nos hacen más humanos. No podemos volver atrás con la tecnología, no estaría bien que lo hiciéramos. Pero sí hoy más que nunca es necesario volver a las fuentes de nuestra propia humanidad, volver a pensarnos a nosotros mismos como espíritus encarnados que necesitamos del contacto real, vital con el otro. Y ese otro es justamente un «otro» que nos impulsa a crecer, a creer, a confiar y a entregarnos gratuitamente por mi bien, por su bien, por el bien de la sociedad.

Cualquier institución necesita de la tecnología. Pero es el hombre el que debe dominar la tecnología. La inteligencia artificial representa un peligro latente si es que pensamos que somos inferiores a la propia creación del hombre. Allí hay un elemento que nos impulsa a tomar el control sobre los inventos humanos. Las instituciones formadoras, desde la escuela hasta la universidad, tienen una responsabilidad primordial en la formación del juicio crítico, en la formación integral del hombre, para que las herramientas tecnológicas, tan útiles a la hora de educar, no pasen a ser el fin y dejen de ser un medio. Porque la finalidad de la educación de la persona es que esa persona sea feliz y plena, fin que trasciende a toda institución educativa.

El problema de nuestra sociedad de con- sumo manejada por los macrodatos es que tendemos a sustituir el intelecto divino por el humano ${ }^{5}$ y allí perdemos el foco, perdemos nuestro lugar, porque fácilmente podemos desligarnos de la responsabilidad que implica tener tantos datos en nuestras manos... y el afán de poder y de control es un riesgo latente que no podemos desoír.

Los sistemas tecnológicos son solo eso: sistemas; circuitos hechos por el hombre para optimizar recursos, afianzar conocimientos, facilitar el intercambio y las comunicaciones. Pero si no hay seres humanos que piensen, sientan, se conmuevan, queden afectados por el otro, el sistema se convierte en un aparato de opresión más que de liberación. Lo «personal», los vínculos encarnados, son irremplazables. Eso es un hecho. Negarlo sería un suicidio.

Por ello, las humanidades son tan necesarias en cualquier institución. Porque nos recuerdan que detrás de todo invento del hombre, deben estar el hombre y su trascendencia, su felicidad que va más allá de los likes del momento. Tenemos una responsabilidad fundamental: dejar una mejor sociedad a las generaciones que vienen. Y esto no se puede lograr sin pensar en el bien del otro en tanto otro, del bien común y de la vida que trasciende a los sistemas.

Lo propiamente humano es personal: cor ad cor loquitur, esto es, el corazón le habla al corazón. Podemos tener un complejo y potente sistema, capaz de reemplazar la labor humana; pero ningún sistema podrá dar cobijo al hom-

\footnotetext{
${ }^{5}$ Con la «muerte de Dios», Nietzsche anticipó las consecuencias: «iDios ha muerto y nosotros somos quienes lo hemos matado! ¿Cómo nos consolaremos, nosotros, asesinos entre los asesinos? Lo que el mundo poseía de más sagrado y poderoso se ha desangrado bajo nuestro cuchillo. ¿Quién borrará de nosotros esa sangre? ¿Qué agua podrá purificarnos? ¿Qué expiaciones, qué juegos nos veremos forzados a inventar? ¿No es excesiva para nosotros la grandeza de este acto? ¿No estamos forzados a convertirnos en dioses, al menos para parecer dignos de los dioses? No hubo en el mundo acto más grandioso y las futuras generaciones serán, por este acto, parte de una historia más alta de lo que hasta el presente fue la historia» (Nietzsche, La Gaya Ciencia, 2003).
} 
bre si no está pensado para el hombre, para que este tenga una vida mejor, plena, donde pueda proyectar su vida desde sí mismo, desde sus afectos y en función del bien común, donde el amor y la paz sean la causa primera y última de estos sistemas. Podemos optimizar las comunicaciones, pero si detrás de las comunicaciones no nos conmueve el hombre con quien nos estamos comunicando, nuestros sistemas se convierten en instrumentos mecánicos y, por ello mismo, despersonalizados.

El gran desafío de nuestra sociedad es apostar por el progreso, por la tecnología, y con el mismo ímpetu, apostar por lo humano, por educar en el juicio crítico, por fomentar ámbitos educativos donde el disenso sea una oportunidad para ampliar horizontes de comprensión, de amor y contención social. Para cuidarnos a nosotros mismos y a las personas que formamos esta sociedad de la que somos parte.

\section{Referencias bibliográficas}

Adorno, T. (1993). Consignas. Buenos Aires: Amorrortu editores.

Arendt, H. (2009). La condición humana. Buenos Aires: Paidós.

Aristóteles. (1985). Ética a Nicómaco. Madrid: Gredos.
Han, B.-C. (2017). La expulsión de lo distinto. Barcelona: Herder.

Komar, E. (2001). Los problemas humanos de la sociedad opulenta. Buenos Aires: Ediciones Sabiduría Cristiana.

Komar, E. (2008). Curso de Metafísica: Inmanencia y trascendencia. Buenos Aires: Ediciones Sabiduría Cristiana.

Komar, E. (2014). La salida del letargo. Buenos Aires: Sabiduría cristiana.

Marcuse, H. (1993). El hombre unidimensional, Ensayo sobre la ideología de la sociedad avanzada. Buenos Aires: Planeta Agostini.

Nietzsche, F. (2003). La Gaya Ciencia (2003 ed.). (P. G. Mantua, Trad.) Barcelona: E1 Barquero.

Nietzsche, F. (2008). El nacimiento de la tragedia $\left(10^{\circ}\right.$ ed.). (E. K. Navascués, Trad.) Madrid: Biblioteca Edaf.

Pieper, J. (1974). El ocio y la vida intelectual. Rialp: Madrid.

Platón. (1993). La República o el Estado (Vigésimo cuarta ed.). (M. Candel, Trad.) Madrid: Espasa Calpe.

Th. W. Adorno y M. Horkheimer . (1998). Dialéctica de la Ilustración. (J. J. Sánchez, Trad.) Madrid: Trotta. 
